\title{
Coil Embolization of an Unruptured Intracranial Aneurysm Associated With Behcet's Disease -Case Report-
}

\author{
Mehmet Faik Ozveren, Yasushi MATSUMOTO*, \\ Ryushi KONDO*, and Akira TAKAHASHI** \\ Department of Neurosurgery, Ankara Ataturk Training and \\ Research Hospital, Ankara, Turkey; \\ *Department of Neuroendovascular Therapy, Kohnan Hospital, Sendai, Miyagi; \\ **Department of Neuroendovascular Therapy, Graduate School of Medicine, \\ Tohoku University, Sendai, Miyagi
}

\begin{abstract}
A 36-year-old male patient with Behcet's disease consulted our hospital for treatment of an unruptured intracranial aneurysm. He was neurologically intact. He had undergone surgery for an aneurysm of the superior mesenteric artery 2 years ago and had been followed up because of the aneurysm of the left radial artery for 1 year. He had been receiving steroid treatment for 4 years. Three-dimensional computed tomography angiography identified an aneurysm of the left intracranial internal carotid artery. The lesion was treated by coil embolization. He was discharged without complications. Intracranial aneurysm formation is extremely rare in patients with Behcet's disease. The presence of extracranial aneurysms indicates screening for intracranial aneurysms. The present case shows that coil embolization can be used to treat unruptured intracranial aneurysm in patients with Behcet's disease.
\end{abstract}

Key words: Behcet's disease, coil embolization, internal carotid artery, unruptured intracranial aneurysm

\section{Introduction}

Behcet's disease is a chronic disorder characterized by recurrent inflammatory attacks and may involve multiple organs. The clinical triad consists of aphthous stomatitis, genital ulceration, and uveitis. ${ }^{10)}$ The incidence rates are higher in Mediterranean countries and the Far East compared to other parts of the world. The vascular lesions occur in 7-29\% of cases of Behcet's disease, 14,16,22,25) and can be divided into four types, arterial occlusion, arterial aneurysm, venous occlusion, and venous varicosity. ${ }^{10,14,17,20,22)}$ Venous lesions usually cause venous thrombosis, which is a common finding of the disease. ${ }^{4,14,16)}$ In contrast, arterial involvement is extremely rare, accounting for about $1.6-12 \%$ of vascular involvement. ${ }^{3,14,16,22)}$ The endovascular treatment of intracranial aneurysms has shown tremendous advances, but few such aneurysms associated with Behcet's disease have been treated by this approach. ${ }^{1,13,23)}$

We describe a case of unruptured intracranial aneurysm in a patient with Behcet's disease treated by endovascular embolization.

Received September 18, 2008;

Accepted April 16, 2009

\section{Case Report}

A 36-year-old male patient consulted the Department of Neuroendovascular Therapy of Kohnan Hospital for treatment of an unruptured intracranial aneurysm. Prednisolone treatment ( $30 \mathrm{mg} /$ day) had been started 4 years previously under a diagnosis of Behcet's disease. The patient
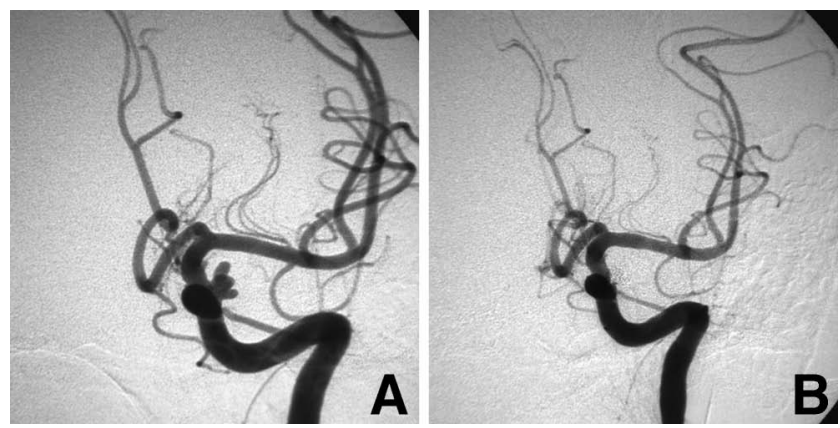

Fig. 1 A: Digital subtraction angiogram showing a multilobulated aneurysm of the left internal carotid artery. B: Postoperative digital subtraction angiogram showing complete occlusion of the aneurysm without compromise of the parent artery. 
had undergone vein graft between the superior mesenteric artery and right iliac artery for an aneurysm of the superior mesenteric artery 2 years previously, and had been followed up for an aneurysm of the left radial artery for 1 year. Three-dimensional computed tomography angiography showed an aneurysm of the left intracranial internal carotid artery (ICA). The patient was hospitalized because of this incidentally found intracranial aneurysm.

Systemic examination revealed oral and genital ulcerations, and neurological evaluation was normal. Cerebral digital subtraction angiography revealed a multilobulated aneurysm of the left ICA (Fig. 1A). Endovascular embolization was performed under local anesthesia. The ICA was catheterized with a $7 \mathrm{~F}$ guiding catheter (Guider; Boston Scientific, Natick, Mass., U.S.A.). A microcatheter (Echelon 10; EV3, Plymouth, Minn., U.S.A.) and occlusion balloon (Hyperglide $4 \times 10 \mathrm{~mm}$; EV3) were introduced into the neck of the aneurysm. Coil embolization was supported by the balloon neck-plasty technique. Three Guglielmi detachable coils (GDCs), GDC10 UltraSoft SR 4 $\mathrm{mm} \times 8 \mathrm{~cm}, 4 \mathrm{~mm} \times 4 \mathrm{~cm}$, and $3 \mathrm{~mm} \times 4 \mathrm{~cm}$ (Boston Scientific), were packed into the aneurysm sac (Fig. 1B). He was discharged without complications on the 9th postoperative day.

\section{Discussion}

Vascular complications associated with Behcet's disease generally manifest clinically 3-16 years after development. ${ }^{14,26)}$ However, intracranial aneurysm may be identified 5 to 18 months before the diagnosis of Behcet's disease is established. ${ }^{1324)}$ Vascular involvement is more frequent in males although Behcet's disease shows no significant sex difference. ${ }^{14,23,25,26)}$ Our male patient was 36 years old and the vascular manifestations became apparent 2 years after the finding of an aneurysm on the superior mesenteric artery. Almost all cases of aneurysm in patients with Behcet's disease manifested as subarachnoid hemorrhage..$^{9,13,15,18,23,24)}$ Recently, a case of unruptured aneurysm of the middle cerebral artery was described which disappeared after steroid therapy for 3 days. ${ }^{11)}$ Our case of aneurysm was first detected as unruptured and was treated by endovascular coiling.

Behcet's disease is a chronic disorder, so intracranial aneurysm may be detected before rupture, as in our case. Intracranial aneurysms are very rare in patients with Behcet's disease, but detection of an extracranial aneurysm may be an important indicator to investigate the intracranial vasculature. Multiple aneurysms may include both intracranial and extracranial aneurysms, ${ }^{13,21)}$ as in our case, but are more likely in either intracranial ${ }^{18,24)}$ or extracranial $^{4-6,8,19)}$ locations. Multiplicity is not rare in the vasculo-Behcet conditions. ${ }^{6,13)}$ Therefore, presence of more than one aneurysm in the patient, anywhere in the body, may indicate the vasculo-Behcet condition, as in our case. We consider that such patients should undergo investigation of the cerebral arteries, preferably by noninvasive three-dimensional multi-slice computed tomography angiography, ${ }^{7)}$ as in our case, or magnetic resonance angiography. The presence of inflammatory changes in the vessel wall may increase the risk of rupture during intraarterial injection of the contrast agent. ${ }^{2)}$ Therefore, less invasive detection techniques may be safer for the diagnosis of intracranial aneurysms in patients with Behcet's disease.

Aneurysm formation associated with arterial inflammation is particularly observed in the abdominal aorta and large arteries such as the femoral and pulmonary arteries. ${ }^{17)}$ The mechanism of aneurysm development involves vasculitis resulting in obliterative endarteritis of the vasa vasorum supplying medium and large vessels. ${ }^{17)}$ Rupture of the internal and external elastic lamina due to thinning of tunica media is an important stage in the beginning of the formation of the aneurysmal dilatation. ${ }^{17)}$ Histological studies of aneurysmal areas in patients with Behcet's disease have shown proliferation of endothelial cells, mononuclear and neutrophilic infiltration, destruction of elastic lamina, fibrinoid necrosis, and thrombus formation. ${ }^{17)}$

Cerebral aneurysms in patients with Behcet's disease can be treated by clipping or coiling. ${ }^{13,15,23)}$ Only a few cases have been treated by coil embolization (Table

Table 1 Cerebral aneurysms treated by coil embolization in patients with Behcet's disease

\begin{tabular}{|c|c|c|c|c|c|}
\hline Author (Year) & $\begin{array}{l}\text { Age } \\
\text { (yrs)/ } \\
\text { Sex }\end{array}$ & $\begin{array}{l}\text { Presenta- } \\
\text { tion }\end{array}$ & $\begin{array}{l}\text { Location of } \\
\text { the aneurysm }\end{array}$ & Endovascular technique & $\begin{array}{l}\text { Follow-up period; } \\
\text { finding }\end{array}$ \\
\hline $\begin{array}{l}\text { Rosenstingl et al. } \\
\left.(2001)^{23}\right)\end{array}$ & $36 / \mathrm{M}$ & $\mathrm{SAH}$ & lt SCA & no explanation & $6 \mathrm{mos}$ \\
\hline \multirow[t]{2}{*}{$\begin{array}{l}\text { Kizilkilic et al. } \\
(2003)^{13)}\end{array}$} & $38 / \mathrm{M}$ & $\mathrm{SAH}$ & rt SCA & $\begin{array}{l}\text { proximal occlusion of the } \\
\text { parent artery by NBCA }\end{array}$ & $\begin{array}{l}1 \mathrm{yr} \text {; no filling of aneurysm, } \\
\text { rt SCA ischemia }\end{array}$ \\
\hline & $55 / \mathrm{M}$ & $\mathrm{SAH}$ & $\begin{array}{l}\text { intracranial } \\
\text { VA }\end{array}$ & $\begin{array}{l}\text { proximal occlusion of VA by } \\
\text { two GDCs }(2 \mathrm{~mm} \times 8 \mathrm{~cm})\end{array}$ & $\begin{array}{l}\text { just after operation; } \\
\text { total occlusion of parent } \\
\text { artery and aneurysm }\end{array}$ \\
\hline Present case & $36 / \mathrm{M}$ & unruptured & lt ICA & $\begin{array}{l}\text { embolization of ICA aneurysm } \\
\text { by three GDCs }(4 \mathrm{~mm} \times 8 \mathrm{~cm} \text {, } \\
4 \mathrm{~mm} \times 4 \mathrm{~cm}, 3 \mathrm{~mm} \times 4 \mathrm{~cm})\end{array}$ & $\begin{array}{l}1 \mathrm{yr} \text {; no filling of aneurysm, } \\
\text { intact parent artery }\end{array}$ \\
\hline
\end{tabular}

ICA: internal carotid artery, NBCA: N-butyl cyanoacrylate, SAH: subarachnoid hemorrhage, SCA: superior cerebellar artery, VA: vertebral artery. 
1). ${ }^{1,13,23)}$ A review of 14 cases of cerebral aneurysms concomitant with Behcet's disease showed half of them were multiple. ${ }^{13)}$ In our opinion, this finding is important for the determination of the treatment modality. These patients seem to be prone to development of new aneurysms. Therefore, approaching the lesion by the endovascular route appears to be more suitable than craniotomy, especially in young patients. Second reason for coiling instead of open surgery was the blister-like shape of the aneurysm on the ICA in our case, since clipping alone may lead to laceration of the ICA wall. Third reason for endovascular approach was the weakness of the aneurysm wall, because of the inflammatory reaction on the involved vessel, could cause clipping catastrophic.

Immunosuppressive and corticosteroid treatments are thought to be essential to prevent vascular complications, ${ }^{4,23,26)}$ and can be added to the surgical treatment of the aneurysm. ${ }^{1,5,13,18,22-24)}$ Colchicine is another drug useful for the prevention of relapses. ${ }^{8,13,23,24)}$ Small aneurysms can be treated successfully by cytotoxic agents and/or steroids. ${ }^{11,18)}$ However, our patient developed multiple aneurysms despite steroid therapy. Several patients with systemic lupus erythematosus have suffered aneurysm rupture during the course of steroid therapy. ${ }^{12)}$ The steroid therapy had been prolonged before the diagnosis of cerebral aneurysms in these patients. Therefore, the disease might have become resistant to the steroid therapy. ${ }^{11)}$ Endovascular intervention in our case was selected because of the finding of the aneurysm with 3 lobules, which indicated high risk of rupture.

\section{Acknowledgment}

Dr. Ozveren thanks the Turkish Neurosurgical Society for a scholarship for neuroendovascular study at Kohnan Hospital and Tohoku University, Japan.

\section{References}

1) Agrawal S, Jagadeesh R, Aggarwal A, Phadke RV, Misra R: Aneurysm of the internal carotid artery in a female patient of Behcet's disease: a rare presentation. Clin Rheumatol 26: 994-995, 2007

2) Aktas EG, Kaplan M, Ozveren MF: Basilar artery aneurysm associated with Behcet's disease: case report. Turk Neurosurg 18: 35-38, 2008

3) Barlett ST, McCarthy WJ, Palmer AS, Flinn WR, Bergan JJ, Yao JS: Multiple aneurysms in Behcet's disease. Arch Surg 123: 1004-1008, 1988

4) Besbas N, Ozyurek E, Balkanci F, Ozen S, Saatci I, Ozaltin F, Bakkaloglu A: Behcet's disease with severe arterial involvement in a child. Clin Rheumatol 21: 176-179, 2002

5) Caballol N, Dominguez A, Vidaller A, Martinez-Yélamos S: [Endovascular treatment of carotid and pulmonary aneurysms in Behçet's disease]. Neurologia 20: 370-373, 2005 (Spa, with Eng abstract)

6) Ceyran H, Akcali Y, Kahraman C: Surgical treatment of vasculo-Behcet's disease. A review of patients with concomitant multiple aneurysms and venous lesions. Vasa 32: 149-153, 2003

7) El Khaldi M, Pernter P, Ferro F, Alfieri A, Decaminada N, Naibo L, Bonatti G: Detection of cerebral aneurysms in nontraumatic subarachnoid haemorrhage: role of multislice CT angiography in 130 consecutive patients. Radiol Med 112: 123-137, 2007

8) Hama $\mathrm{Y}$, Kaji T, Iwasaki $\mathrm{Y}$, Kawauchi T, Yamamoto $\mathrm{M}$, Kusano S: Endovascular management of multiple arterial aneurysms in Behcet's disease. Br J Radiol 77: 615-619, 2004

9) Ildan F, Gocer AI, Bagdatoglu H, Tuna M, Tuna M, Karadayi A: Intracranial arterial aneurysm complicating Behcet's disease. Neurosurg Rev 19: 53-56, 1996

10) International Study Group for Behcet's disease: Criteria for diagnosis of Behcet's disease. Lancet 335: 1078-1080, 1990

11) Kaku Y, Hamada JI, Kuroda JI, Kai Y, Morioka M, Kuratsu JI: Multiple peripheral middle cerebral artery aneurysms associated with Behcet's disease. Acta Neurochir (Wien) 149: 823-827, 2007

12) Kawamata $T$, Kagawa M, Kubo O, Takeshita M, Ujiie H, Sato K, Izawa M: [Clinicopathological studies of three cases of cerebral aneurysms associated with systemic lupus erythematosus]. No Shinkei Geka 19: 633-639, 1991 (Jpn, with Eng abstract)

13) Kizilkilic O, Albayram S, Adaletli I, Ak H, Islak C, Kocer N: Endovascular treatment of Behçet's disease-associated intracranial aneurysms: report of two cases and review of the literature. Neuroradiology 45: 328-334, 2003

14) Koc Y, Gullu I, Akpek G, Akpolat T, Kansu E, Kiraz S, Batman F, Kansu T, Balkanci F, Akkaya S: Vascular involvement in Behcet's disease. J Rheumatol 19: 402-410, 1992

15) Kocak A, Caylı SR, Ates O, Sarac K: Middle cerebral artery aneurysm associated with Behcet's disease: case report. Neurol Med Chir (Tokyo) 44: 368-371, 2004

16) Kuzu MA, Ozaslan C, Koksoy C, Gurler A, Tuzuner A: Vascular involvement in Behcet's disease: 8-year audit. World J Surg 18: 948-954, 1994

17) Matsumoto T, Uekusa T, Fukuda Y: Vasculo-Behcet's disease: a pathologic study of eight cases. Hum Pathol 22: 45-51, 1991

18) Nakasu S, Kaneko M, Matsuda M: Cerebral aneurysms associated with Behcet's disease: a case report. J Neurol Neurosurg Psychiatry 70: 682-684, 2001

19) Normayah K, Mazri YM, Suib I, Zainal AA: Behcet's disease with vascular complications. Med J Malaysia 59: 547-549, 2004

20) Ohori N, Toda K, Ohta S, Yoshimura T: [A case of Behcet's disease presenting cerebral infarction due to occlusions of the bilateral internal carotid arteries]. Rinsho Shinkeigaku 39: 856-859, 1999 (Jpn, with Eng abstract)

21) Ohshima $T$, Miyachi $S$, Hattori $K$, Iizuka $H$, Izumi $T$, Nakane Y, Aimi Y, Yoshida J: A case of giant common carotid artery aneurysm associated with vascular Behcet disease: successfully treated with a covered stent. Surg Neurol 69: 297-301, 2008

22) Park JH, Han MC, Bettmann MA: Arterial manifestations of Behcet disease. AJR Am J Roentgenol 143: 821-825, 1984

23) Rosenstingl S, Dupuy E, Alves O, George B, Tobelem G: Maladie de Behcet revelee par un anevrisme intracranien. Rev Med Interne 22: 177-182, 2001 (Fre, with Eng abstract)

24) Senel A, Cokluk C, Gunduz C, Yildiz A, Celik F: Cerebral aneurysms in Behcet's disease: a case report. Minim Invasive Neurosurg 46: 361-362, 2003

25) Tursen U, Gurler A, Boyvat A: Evaluation of clinical findings according to sex in 2313 Turkish patients with Behçet's disease. Int J Dermatol 42: 346-351, 2003

26) Tuzun H, Besirli K, Sayin A, Vural FS, Hizli N, Yazici H: Management of aneurysms in Behcet's syndrome: an analysis of 24 patients. Surgery 121: 150-156, 1997

Address reprint requests to: Yasushi Matsumoto, M.D., Department of Neuroendovascular Therapy, Kohnan Hospital, 4-20-1 Nagamachi-minami, Taihaku-ku, Sendai 982-8523, Japan.

e-mail: matsumoto@kohnan-sendai.or.jp 